\title{
Safer Spaces: The impact of a reduction in road fatalities on the life expectancy of South Africans
}

\author{
LILIANA DE ABREU \\ ANKE HOEFFLER
}

\section{Stellenbosch Economic Working Papers: WP18/2020}

www.ekon.sun.ac.za/wpapers/2020/wp182020

October 2020

KEYWORDS: road traffic fatalities, road safety, life expectancy, South Africa

JEL: I15, I18, J19, O55

DEPARTMENT OF ECONOMICS

UNIVERSITY OF STELLENBOSCH

SOUTH AFRICA

A WORKING PAPER OF THE DEPARTMENT OF ECONOMICS AND THE BUREAU FOR ECONOMIC RESEARCH AT THE UNIVERSITY OF STELLENBOSCH

www.ekon.sun.ac.za/wpapers 


\title{
Safer Spaces: The impact of a reduction in road fatalities on the life expectancy of South Africans
}

\author{
Liliana de Abreu* and Anke Hoeffler \\ Department of Politics and Public Administration \\ University of Konstanz \\ *Corresponding author: \\ Liliana Abreu \\ Universitätsstrasse 10 \\ 78464 Konstanz \\ liliana.abreu@uni-konstanz.de
}

\begin{abstract}
In this paper we determine the cost of fatalities resulting from road traffic injuries (RTIs) in South Africa. We express the costs in terms of reduced life expectancy and years of potential life lost (YPLL). Our main data source is the Injury Mortality Survey, a retrospective descriptive study carried out in 2009 in South Africa. Using the mortality rates by sex and age from the mortuary data we calculate actual life expectancy at birth. In our counterfactual analysis we assume a reduction of $15 \%$ reduction per year in road fatalities for a period of 10 years. A comparison of the estimated actual and counterfactual life expectancies suggests that the average gain in life expectancy at birth would be 0.58 years. Since the overwhelming majority of road traffic fatalities are male (75.7\%), there is a considerable gender difference. Men would gain 0.85 years while women would gain 0.30 years in life expectancy, closing the gender gap in life expectancy by about $14 \%$. We then discuss how a reduction in RTIs could be achieved. South Africa's legislation already covers all important aspects of road safety (e.g. seat belt use, drink driving restrictions, speed limits, infrastructure improvements), however, enforcement is relatively weak and should be improved. There are a raft of measures that have been well researched in other countries, most interventions aim to modify the behaviour of road users and have been found to be cost effective. In addition to stricter enforcement, evidence from social science suggests that compliance could be increased through a change in social norms regarding road usage.
\end{abstract}

Keywords: road traffic fatalities, road safety, life expectancy, South Africa

JEL Codes: I15, I18, J19, O55

This research is supported by the Alexander von Humboldt Foundation. We are grateful for comments and suggestions from Stijn Daniels, Howard Friedman, Richard Matzopulous, John Symons and participants of the "Road Safety Workshop" in Stellenbosch, 19-20 Feb 2020. Betül Özturan and Lennart Gießing provided excellent research assistance. All remaining errors are our own. 


\section{INTRODUCTION}

Road traffic injuries (RTIs) are a global public health problem (Peden et al. 2004). Worldwide, about 1.35 million people are killed and about 50 million are injured on the roads every year. This accounts for almost a quarter of all injury and violence-related deaths globally (WHO 2018). RTIs are among the top 10 primary causes of disability-adjusted life years (DALYs) lost and are now the leading cause of death for children and young adults aged 5-29 years. Young men are at a much higher risk, more than three-quarters of the road traffic deaths occur among young males, with rates of death and DALYs lost being much higher amongst males than females (WHO 2014).

In South Africa road safety is particularly poor, e.g. in 2012 there were almost 17,600 road deaths, making RTIs one of the main causes of morbidity and mortality comparable to HIV/AIDS, homicides and some chronic diseases, occupying a place in the top ten ( $9^{\text {th }}$ place) of the leading causes of death (Pillay-van Wyk et al. 2016b). The International Transport Forum at the OECD ranked South Africa the worst out of 36 African countries, due to the high number of road fatalities (IRTAD 2020). RTIs account for $3.26 \%$ of total deaths in South Africa (IHME 2018), resulting in high human and socio-economic costs for the country. South Africa is a signatory to the United Nations (UN) Decade of Action for Road Safety 2011-2020. As such, the country has committed itself to reducing fatalities by $50 \%$ by the year 2020 . However, the Government's Arrive Alive Road Safety campaign proposed an even more ambitious RTI reduction of $15 \%$ a year (Arrive Alive 2010), corresponding to an overall reduction of $80 \%$ during the period 2010-2020. Indeed, South Africa has made some progress in reducing the total number of road crash fatalities from their peak in 2006. According to latest data from the Road Traffic Management Corporation (RTMC), there were 12,921 reported road fatalities in 2018, representing an $8 \%$ decrease when compared to 2017 . However, the number of traffic deaths per 100,000 inhabitants are high and increased by $18 \%$ between 2000 and 2018. In 2018, 28.23 traffic deaths per 100,000 inhabitants were recorded (IHME 2018), compared to 19.9 in 1990 (IRTAD 2020). These are alarming statistics when compared to other upper middle income countries. Take for example Colombia, where during the period 1996 and 2006 the number of traffic deaths was reduced by $50 \%$. The implementation of an integrated approach to road safety and urban mobility (WHO 2018) decreased Colombia's road fatality rate to 18.8/100,000 inhabitants (WHO 2019).

The aim of this paper is to determine the cost of fatalities resulting from RTIs in South Africa. We assess these costs by comparing the actual data with a counterfactual scenario, where fatalities from RTIs decreased by $80 \%$. The costs are expressed in terms of reduced life expectancy and years of potential life lost. This paper is organized in the following way. In Section 2 we discuss data and methods and Section 3 presents the results. Section 4 provides a discussion of the drivers of the high RTIs in SA and how these could be reduced. The last section concludes. 


\section{DATA AND METHODS}

\subsection{DATA}

\section{Life Expectancy}

An increase in life expectancy is interpreted as increased individual and social welfare. Improved health and longer lives increase productivity, household wealth and social cohesion through intergenerational transmission of knowledge and norms. As one of the most frequently used demographic indicators, life expectancy is a statistical measure of the average time a person is expected to live at a given age under given age-specific mortality rates. For most of the twentieth century, life expectancy increased in nearly every part of the world (UN 2019a). In South Africa, life expectancy decreased substantially from 1990 to 2004, mainly as a result of HIV/AIDS and the associate rise in Tuberculosis. In 1991 life expectancy at birth in South Africa was 63.38 years, but over the subsequent years it decreased to 53.44 years in 2004 (see Figure 1), when expanded access to antiretrovirals for treatment of HIV began to reverse this trend (Bor et al. 2015; UN 2019b; WHO 2020).

Figure 1. Life expectancy in South Africa 1990-2020

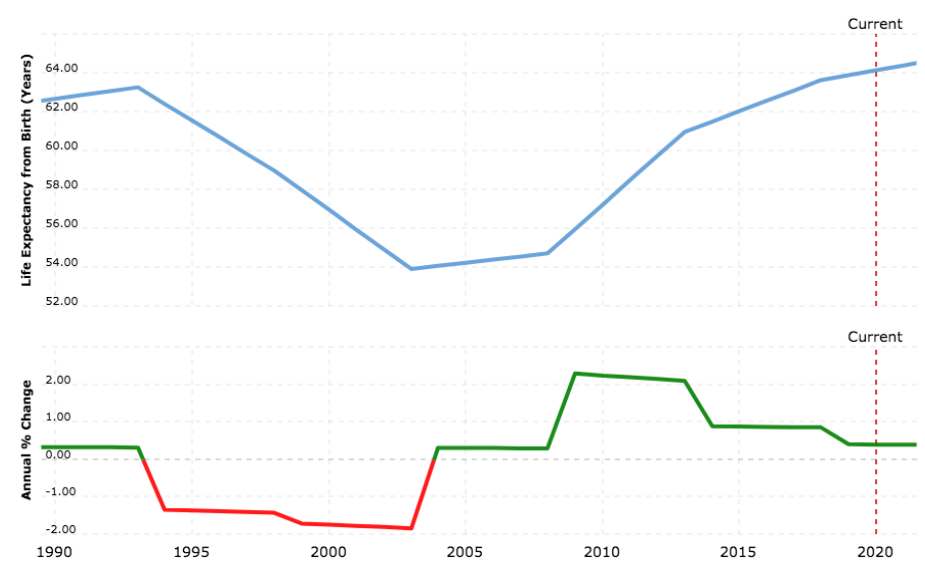

Source: United Nations - World Population Prospects (UN 2019)

Road Traffic Injuries (RTIs)

Although RTIs are an important cause of mortality in South Africa, the impact on life expectancy is still poorly understood. One of the reasons for this knowledge gap is that reliable data for RTIs are difficult to obtain. Since the early 1990s, studies have identified and addressed deficiencies in the registration of deaths in South Africa (Dorrington et al. 2001). One of the main reasons for unreliability of the data is the misclassification of injury deaths. In order to address this issue Richard Matzopoulos and colleagues conducted a nationally representative study of injury deaths using postmortem reports from mortuaries as well as police reports and hospital records. Their study suggests that there are major discrepancies between the actual and recorded causes of death. While Statistics South Africa classified nearly two-thirds (63.9\%) of injury deaths as being due to 'other external causes of accidental injury', with $11.5 \%$ caused by transport injuries, the Injury Mortality Survey demonstrated that 
transport accounted for 33.8\% of all injury deaths (Matzopoulos et al. 2013a). Our investigation of more recent Statistics South Africa cause-of-death data showed that despite a slight decrease of other unintentional injury deaths, the problem of misclassification of traffic deaths as other unintentional injuries appears to persist. Thus, we do not trust the more recent official statistics and decided to use the data from the Injury Mortality Survey from 2009 to analyze the impact of road fatalities on live expectancy. One drawback of the Injury Mortality Survey is that the data are only available for one year, 2009. These data limitations prevent us from comparing actual and counterfactual outcomes over time, as for example the study by (Sharkey und Friedson 2019) on the impact of homicide decline on life expectancy in the US. More discussion on data quality can be found in the Appendix.

\subsection{METHODS}

Using population data from Statistics South Africa and injury deaths from Matzopoulos et al. (2015a) we first estimate life expectancy at birth and then calculate the hypothetical gains in life expectancy if RTIs were reduced by $80 \%$. We have sufficiently age-disaggregated data to calculate life expectancy for men as well as for women separately but insufficient information to calculate life expectancy by race or region. Data were analyzed using $\mathrm{R}$ Statistical Software.

We use the standard method to estimate life expectancy at birth for South Africa population of males and females in all age groups (Preston et al. 2000). This method consists of using an iterative process to create a life table that calculates the lifespans of 100,000 hypothetical individuals, on the basis of age and gender specifics mortality rates. Deaths during each year of age $(x)$, from 0 to 99 , are calculated as $d_{x}=l_{x} \times q_{x}$. The number of survivors to age $x$ is $l_{x} ; q_{x}$ is a person's risk of dying between reaching ages $x$ and $x+1$; and $d_{x}$ is the number of individuals dying between reaching ages $x$ and $x+1$. Assuming 100,000 births (i.e., $\left.l_{0}=100,000\right)$, Eq. (1) shows the calculation of the number of survivors to each year of age, from 1 to 100: $L_{x}=l_{x-1}-d_{x-1}$. For all deaths happening beyond the first year of life, death is assumed to occur precisely halfway through the year of life in which the individuals die. Those dying in their first year are assigned the average lifetime of all persons who die in their first year. Survivors to age 100 are given the sex and age specific life expectancy at age 100. Life expectancy at birth is calculated as

$$
L E_{0}=\frac{\sum_{c=0}^{99} d_{x}\left(x+c_{x}\right)+\left(l_{100} \times\left(100+L E_{100}\right)\right)}{100,000}
$$

where life expectancy $y_{0}$ is life expectancy at birth; $c_{x}$ equals 0.5 for all values of $x$ from 1 to $99 ; c_{0}$ equals the average lifetime of those dying in their first year of life; and $L E_{100}$ is life expectancy at age 100.

We then recalculated life expectancies at birth under the counterfactual assumption that mortality rates due to road crashes decreased by $80 \%$. Accordingly, we calculate age and sex specific counterfactual mortality rates for each year of age $(x)$, as in Eq. (4):

$$
m_{x}^{\prime}=m_{x}+\left(\left(M_{x}^{\prime}-M_{x}\right) \times\left(1-\left(m_{x}-M_{x}\right)\right)\right)
$$


$m_{x}{ }^{\prime}$ and $m_{x}$, respectively, are the counterfactual and actual mortality rates; and $M_{x}{ }^{\prime}$ and $M_{x}$, respectively, at the counterfactual and actual rates of mortality from RTIs. We then convert these counterfactual mortality rates to counterfactual risks of dying $\left(q_{x}^{\prime}\right)$ and construct life tables based on these risks.

An alternative measure of the costs of road traffic injuries is the number of Years of Potential Life Lost (YPLL). The YPLL estimates the average time a person would have lived had he or she not died prematurely and can thus be used to help quantify social and economic loss owing to premature death. Thus, YPLL from road fatalities per 100,000 births is calculated by sex, standardized for the population's age distribution to allow comparisons over time and between groups (Aragón et al. 2008). We calculate YPLL, as follows:

$$
Y P L L_{x}=\frac{D_{x} \times\left(L E_{x}-C_{x}\right)}{p_{x}} \times 100,000
$$

Where $D_{x}$ is the number of road fatalities deaths at age $x, L E_{x}$ is life expectancy at age $x, C_{x}$ is the average time (in years) since the last birthday of a road fatality victim of age $x$, and $p_{x}$ is the population of age $x$. In this formulation, a road crash is considered premature by $\left(L E_{x}-C_{x}\right)$ years, the difference between the average life expectancy of the road traffic victim and the person's age (Aragón et al. 2008). We calculate the YPLL for the actual number of deaths as well as the YPLL if road fatalities were reduced.

\section{RESULTS}

We present our main results in three tables. Table 1, Column (1) lists the age group, column (2) the total number of deaths from RTIs, column (3) our estimated life expectancy based on these fatalities, column (4) the estimates of the counterfactual life expectancy assuming a $80 \%$ reduction in deaths from RTIs, column (5) the years of potential life gained due to the reduction in road traffic fatalities (difference columns 4-3), and finally the number of YPLL averted considering the reduction in road fatalities. Tables 2 and 3 lists the same estimates for males and females, respectively.

We calculate life expectancy using the data from the Injury Mortality Survey (Matzopoulos et al. 2013a) providing an estimate of life expectancy at birth of 57.23 years. Note that this is comparable but slightly higher than the UN's estimate of 56.46 years for the year 2009 (UN 2019b). There were a total of 17,103 deaths attributable to road traffic crashes, if these had been reduced, the gains in life expectancy at birth would have been 0.58 years. Gains to young people are considerable, in particular for the age group 15 to 29 years, where the gains of YPLL is highest $(16,061)$.

In Tables 2 and 3 we disaggregate the data by sex and calculate life expectancy at birth as 54.91 years for males and 59.37 years for females. Men were much more likely to die from road traffic injuries than women: 12,942 (75.7\%) of all the road traffic victims were male and 4,135 (24.1\%) female. Given that a much greater proportion of RTI deaths are male it is not surprising that men stand to gain much more from a reduction. Our counterfactual analysis shows, that life expectancy at birth for men would increase by 0.85 years and for women by 0.30 years. If fatalities from RTIs were reduced this would not only increase the life expectancy for men and women, it would 
also help to close the gap between male and female life expectancy. According our estimates the gap between male and female life expectancy would be reduced by $14 \%$.

Table 1. Actual and counterfactual years of life expectancy at birth in 2009

\begin{tabular}{|c|c|c|c|c|c|}
\hline \multicolumn{6}{|l|}{2009} \\
\hline Age in years & $\begin{array}{l}\text { Total deaths } \\
\text { (RTIs) }\end{array}$ & $\begin{array}{l}\text { Calculated } \\
\text { actual life } \\
\text { expectancy }^{\text {a }}\end{array}$ & $\begin{array}{l}\text { Counterfactual } \\
\text { life } \\
\text { expectancy }^{b}\end{array}$ & $\begin{array}{l}\text { Gains life } \\
\text { expectancy } \\
\text { (years) }\end{array}$ & $\begin{array}{l}\text { Years of } \\
\text { Potential Life } \\
\text { Lost averted }\end{array}$ \\
\hline $0-4$ & 734 & $\begin{array}{l}57.23 \\
(56.9 \text { to } 57.6)\end{array}$ & $\begin{array}{l}57.81 \\
(57.4 \text { to } 58.2)\end{array}$ & 0.58 & 3,204 \\
\hline $5-15$ & 1,041 & $\begin{array}{l}55.14 \\
\text { (54.8 to } 55.4)\end{array}$ & $\begin{array}{l}55.71 \\
(55.4 \text { to } 56)\end{array}$ & 0.57 & 3,804 \\
\hline $15-29$ & 5,452 & $\begin{array}{l}45.57 \\
(45.4 \text { to } 45.7)\end{array}$ & $\begin{array}{l}46.11 \\
(46 \text { to } 46.2)\end{array}$ & 0.64 & 16,106 \\
\hline $30-44$ & 5,178 & $\begin{array}{l}33.58 \\
\text { (33.4 to 33.7) }\end{array}$ & $\begin{array}{l}33.96 \\
(33.8 \text { to } 34.1)\end{array}$ & 0.38 & 14,690 \\
\hline $45-59$ & 2,762 & $\begin{array}{l}26.25 \\
\text { (26.1 to 26.4) }\end{array}$ & $\begin{array}{l}26.46 \\
\text { (26.3 to 26.6) }\end{array}$ & 0.21 & 7,030 \\
\hline+60 & 1,270 & $\begin{array}{l}19.25 \\
\text { (19 to } 19.5 \text { ) } \\
\end{array}$ & $\begin{array}{l}19.34 \\
(19.1 \text { to } 19.6)\end{array}$ & 0.09 & 2,392 \\
\hline Unknown & 666 & & & & \\
\hline Total & 17,103 & & & & 47,226 \\
\hline
\end{tabular}

Notes: Data source "The Injury Mortality Survey 2009", own calculations. ${ }^{\text {a }}$ - Actual Life expectancy in 2009 is calculated for each age group by sex, ${ }^{\mathrm{b}}-$ Counterfactual life expectancies are based on calculations with a hypothetical reduction of $80 \%$ of road fatalities. $95 \%$ Confidence Interval in brackets

Table 2. Actual and counterfactual years of life expectancy at birth in 2009 for males

\begin{tabular}{|c|c|c|c|c|c|}
\hline 2009 & Males & & & & \\
\hline Age in years & $\begin{array}{l}\text { Total deaths } \\
\text { (RTIs) }\end{array}$ & $\begin{array}{l}\text { Calculated } \\
\text { actual life } \\
\text { expectancy }\end{array}$ & $\begin{array}{l}\text { Counterfactual } \\
\text { life } \\
\text { expectancy }^{b}\end{array}$ & $\begin{array}{l}\text { Gains life } \\
\text { expectancy } \\
\text { (years) }\end{array}$ & $\begin{array}{l}\text { Years of } \\
\text { Potential Life } \\
\text { Lost averted }\end{array}$ \\
\hline $0-4$ & 417 & $\begin{array}{l}54.91 \\
\text { (54.4 to } 55.4 \text { ) }\end{array}$ & $\begin{array}{l}55.75 \\
\text { (55.3 to } 56.2 \text { ) }\end{array}$ & 0.85 & 3,426 \\
\hline $5-15$ & 637 & $\begin{array}{l}52.81 \\
\text { (52.4 to } 53.2 \text { ) }\end{array}$ & $\begin{array}{l}53.66 \\
\text { (53.3 to } 54)\end{array}$ & 0.85 & 4,396 \\
\hline $15-29$ & 4,215 & $\begin{array}{l}43.24 \\
\text { (43.1 to } 43.4 \text { ) }\end{array}$ & $\begin{array}{l}44.05 \\
\text { (43.9 to } 44.2 \text { ) }\end{array}$ & 0.81 & 23,541 \\
\hline $30-44$ & 4,207 & $\begin{array}{l}30.78 \\
\text { (30.6 to 30.9) }\end{array}$ & $\begin{array}{l}31.35 \\
\text { (31.2 to } 31.5)\end{array}$ & 0.57 & 22,461 \\
\hline $45-59$ & 2,115 & $\begin{array}{l}23.63 \\
\text { (23.4 to } 23.8 \text { ) }\end{array}$ & $\begin{array}{l}23.94 \\
\text { (23.7 to } 24.2 \text { ) }\end{array}$ & 0.31 & 9,690 \\
\hline+60 & 818 & $\begin{array}{l}18.19 \\
\text { (17.8 to } 18.5)\end{array}$ & $\begin{array}{l}18.32 \\
\text { (18 to } 18.7)\end{array}$ & 0.13 & 2,835 \\
\hline Unknown & 534 & & & & \\
\hline Total & 12,942 & & & & 66,349 \\
\hline
\end{tabular}

Notes: Data source "The Injury Mortality Survey 2009", own calculations. a - Actual Life expectancy in 2009 is calculated for each age group by sex, $b$ - Counterfactual life expectancies are based on calculations with a hypothetical reduction of $80 \%$ of road fatalities. $95 \%$ Confidence Interval in brackets.

In addition to the differences in potential gains in life expectancy, sex differences across all age groups in terms of changes in YPLL are statistically significant; males consistently lose a greater number of years to crash fatalities than females. 
Counterfactual YPLL analysis shows that if road fatalities were drastically reduced by $80 \%$, South African males would gain 66,349 YPLL and South African females would gain 24,744 YPLL (Tables 2 and 3). Young males aged between 15 to 29 years are the category with the highest gains in YPLL (23,541 years, Table 2). Children under 4 years old would gain more years of potential life (3,204 years), than people over 60 years old (2,392 years, Table 1). For both sexes the age category that would gain most in terms of years of potential life lost is age 15 to 29 years with total YPLL gains of 16,106 (Table 1).

Table 3. Actual and counterfactual years of life expectancy at birth in 2009 for females

\begin{tabular}{|l|l|l|l|l|l|}
\hline 2009 & Females & & & & \\
\hline Age in years & $\begin{array}{l}\text { Total } \\
\text { deaths } \\
\text { (RTIs) }\end{array}$ & $\begin{array}{l}\text { Calculated actual } \\
\text { life expectancy }\end{array}$ & $\begin{array}{l}\text { Counterfactual } \\
\text { life } \\
\text { expectancy }\end{array}$ & $\begin{array}{l}\text { Gains life } \\
\text { expectancy } \\
\text { (years) }\end{array}$ & $\begin{array}{l}\text { Years of } \\
\text { Potential Life } \\
\text { Lost averted }\end{array}$ \\
\hline $0-4$ & 317 & $\begin{array}{l}59.37 \\
(58.8 \text { to } 59.9)\end{array}$ & $\begin{array}{l}59.67 \\
(59.1 \text { to } 60.2)\end{array}$ & 0.30 & 2,872 \\
\hline $5-15$ & 404 & $\begin{array}{l}57.27 \\
(56.8 \text { to } 57.8)\end{array}$ & $\begin{array}{l}57.55 \\
(57.1 \text { to } 58)\end{array}$ & 0.28 & 3,109 \\
\hline $15-29$ & 1,237 & $\begin{array}{l}47.69 \\
(47.4 \text { to } 48)\end{array}$ & $\begin{array}{l}47.94 \\
(47.7 \text { to } 48.2)\end{array}$ & 0.25 & 7,664 \\
\hline $30-44$ & 971 & $\begin{array}{l}36.20 \\
(35.9 \text { to } 36.5)\end{array}$ & $\begin{array}{l}36.37 \\
(36.1 \text { to } 36.7)\end{array}$ & 0.17 & 5,761 \\
\hline $45-59$ & 647 & $\begin{array}{l}28.58 \\
(28.2 \text { to } 29)\end{array}$ & $\begin{array}{l}28.70 \\
(28.3 \text { to } 29.1)\end{array}$ & 0.12 & 3,543 \\
\hline+60 & 452 & $\begin{array}{l}20.10 \\
(19.6 \text { to } 20.6)\end{array}$ & $\begin{array}{l}20.17 \\
(19.7 \text { to } 20.6)\end{array}$ & 0.07 & 1,795 \\
\hline Unknown & 106 & & & & \\
\hline Total & 4,135 & & & & 24,744 \\
\hline
\end{tabular}

Notes: Data source “The Injury Mortality Survey 2009”, own calculations. " - Actual Life expectancy in 2009 is calculated for each age group by sex, ${ }^{\text {b }}$ - Counterfactual life expectancies are based on calculations with a hypothetical reduction of $80 \%$ of road fatalities. $95 \%$ Confidence Interval in brackets.

Since the data are only available by age and sex and not by age and race or location, we cannot comment on the specific effects of RTI reduction by race or location. We can only make the following general observations. The majority of the fatalities $(79.8 \%)$ were black, this corresponds to the share of blacks in the total population $(79.3 \%)$. Thus, it appears that the majority black population is no more at risk from RTIs than other population groups in South Africa. The location information suggests that most part of the fatalities occurred in rural areas (59.8\%) (Matzopoulos et al. 2013a).

\section{DISCUSSION}

Our estimates suggest that RTIs significantly reduce life expectancy and contribute to YPLL. While other injury related deaths have declined, the number of road traffic deaths has remained fairly constant since the late 1990s (Pillay-van Wyk et al. 2016a; Prinsloo 2019), reflecting that the implemented strategies are not working. In this section we present a discussion of the burden that RTIs place on South African society, the most promising strategies to reduce this burden and why current strategies are failing to achieve the desired targets. 
High numbers of traffic injuries and deaths translate into high human costs. Injuries cause pain and suffering to the individual and lead to loss of income. Considering that $51 \%$ of the victims are younger males (age between 15 to 44 years), i.e. a group with high earning potential, (temporary) loss of income increases the risk of poverty for the affected households. In addition to the individual's pain and loss of income, the psychological trauma of losing a child, a spouse or other close family member can disrupt family stability (Verster und Fourie 2018). The high prevalence of injuries and death on the roads therefore place a high socio-economic burden on South Africa and for 2015 the total cost of road traffic injuries was estimated to be ZAR 142.95 billion (approximately EUR 7.3 billion) (Verster und Fourie 2018). This is a large number, but how can this be put into context? Cost estimates depend on a number of different assumptions, such as which price to put on life and injury and which discount rate to use. So far health economists have not developed a standard method of calculating these costs (Friedman 2020). One simple way of comparing cost estimates across countries is to express them as a percentage of national output (for a discussion see Wijnen et al. 2019). This suggests that RTI costs are equal to 3.4\% of South Africa's gross domestic product (GDP). This is one of the highest estimates when compared to other country studies (Du Plessis et al. 2020; Wijnen et al. 2019).

Thus, RTIs place considerable burden on South Africa's society and health care system which is already faced with a number of other public health challenges, such as HIV/AIDs, tuberculosis, injuries resulting from violence and, more recently, Covid-19. If current trends continue, by 2040 RTIs could become the third leading cause of death in South Africa (Foreman et al. 2018). In many ways RTIs are a lesser societal challenge than communicable diseases or violence because there is considerable knowledge regarding road safety interventions. The WHO (WHO 2017) provides a technical package on road safety and lists the main risk factors for RTIs: Speed, drink driving, helmet wearing, seat-belts, child restraints, road infrastructure and vehicle safety standards. A number of interventions are highly effective in reducing mortality rates: seat belt usage reduces fatality rates by $40 \%$, helmet usage by $36 \%$, alcohol limit enforcement by $25 \%$, enforcement of speed limits by $14 \%$, better preparation of novice drivers (i.e. graduated licensing scheme) by $20 \%$ and building better road infrastructure by $15 \%$ (effectiveness rates based on the literature review in (Symons et al. 2019). Daniels et al. (2019) conducted cost-benefit analyses (CBAs) for 29 road safety measures in three different scenario's. Different assumptions of prices and expected effects suggest that 14 measures remained cost-effective in all scenarios, these include enforcement and campaigns on seatbelt wearing, installation of speed bumps and treatment of high risk sites.

Daniels et al. (2019) focus on EU countries but could provide a benchmark for a South African study. This is important, because as Wesson et al. (2016) point out there is little knowledge so far on which interventions would be (1) most effective in reducing RTIs and (2) cost effective in South Africa. In their cross-country comparison (Symons et al. 2019) focus on reducing RTIs for young people and conduct a benefit-cost analysis of a policy package (increased seat belt and helmet usage as well as improved enforcement of alcohol rules and speed restrictions). For the 75 countries in their study they find benefit-cost ratios (BCRs) ranging from 1.4 to 10.9 where South Africa has the 12th highest BCRs (personal communication with John Symons). In her study on South Africa Prinsloo (2019) also focuses on interventions targeting the young. Since younger drivers pose particularly high risks to themselves and others, one of the recommendations is that South African younger drivers would benefit from a Graduated Drivers Licensing (GDL) system. This system gradually exposes the new driver to complex driving situations in a safe manner and has shown to reduce the risk of fatal crash or serious injury in New Zealand, United Sates and Australia (Bates et al. 2014). The main difference from the current licensing system in South 
Africa is that after the learning phase, the driver receives a provisional license (e.g. with night driving restrictions) for a while instead of a full open license. More generally, Prinsloo (2019) suggests that in South Africa the main challenge is the incorporation of human, vehicle and environment factors during the pre-crash, crash and postcrash phase (Haddon, 1968) and that a systems approach is needed to reduce risk exposure, preventing the occurrence and reducing the severity of an injury. A closer collaboration between the Department of Health, the Department of Transport and other public and private agencies is therefore crucial to establish partnerships to design and implement sustainable interventions (Prinsloo 2019).

Figure 2: Deaths by road user category in South Africa

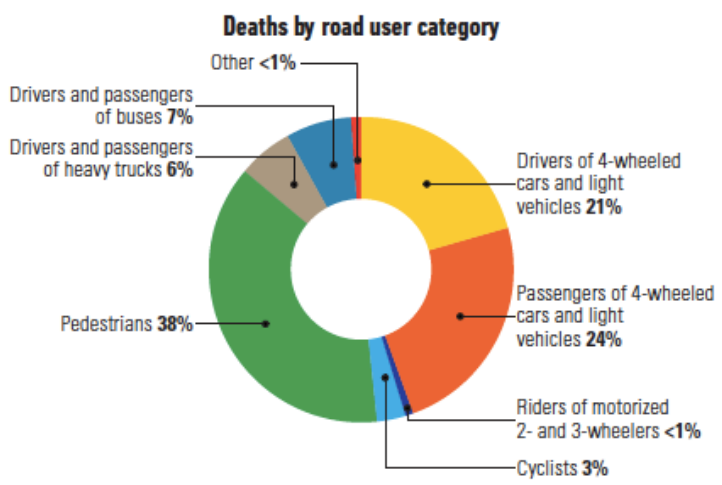

Source: Road Traffic Management Corporation (RTMC), 2016

One of the few studies on middle income countries in Asia and Eastern Africa also confirms the cost effectiveness of road safety interventions (Ralaidovy et al. 2018), however, for maximum impact policy packages should be specifically designed to the South African situation. Figure 2 provides a breakdown of the causes of death by road user category, about $45 \%$ of victims are car drivers and passengers and $38 \%$ are pedestrians. The number of deaths due to bicycle, moped and other two wheelers is relatively low (4\%). Thus, in the first instance road safety strategies should focus on making roads safer for car drivers and pedestrians. The main causes of South Africa's poor road safety outcomes have been identified as risky behaviour by pedestrians, drink driving and low seat belt use. Risky behaviour is often caused by insufficient infrastructure, such as few pedestrian crossings and no sidewalks, while the other two issues are due to poor choices, in 2016 seat belt use is only at $33 \%$ and almost $58 \%$ of all road deaths were attributable to alcohol (WHO 2018). Recent evidence suggests that alcohol restrictions may be reducing RTIs. As an effort to control the spread of Covid-19, and also to reduce the high levels of interpersonal violence during the pandemic, in mid-March 2020 South Africa imposed strict measures for alcohol sales and during national lockdown the sale of all liquors were forbidden. Early reports confirmed a significant reduction in trauma unit admissions for alcohol-related injury, which might include reductions of road traffic injuries as well (Isaacs 2020); (Matzopoulos et al. 2020).

More generally, legislation to mitigate key risk factors is important and South Africa has legislation covering all important aspects (speeding, drink driving, the use of helmets, seat-belts and child restraints) but enforcement rates 
are judged to be mediocre in an international comparison (WHO 2018). One important area of policy improvement is therefore more stringent enforcement of existing rules. Take the example of speeding and other traffic offences: Payment of fines are poorly enforced, traffic authorities acknowledge that fewer than $20 \%$ of fines are paid in the time frame set (AARTO, undated as cited in Du Plessis et al. 2019a). Experimental evidence suggests that payment rates could be improved when motorists are offered the option of a discount on timely payment (Du Plessis et al. 2019a). However, better enforcement may not fully solve problems of compliance, since this is not only influenced by the risk of detection and the monetary and legal consequences, but also by social norms (Du Plessis et al. 2020). There is limited knowledge on social norms regarding road usage but recent survey evidence suggests that many non-payers of fines believe (1) the police to be corrupt, (2) that not all road users are treated fairly and (3) that many motorists do not pay their fines and experience little or no consequences. These beliefs influence values, norms and eventually, behaviour (Du Plessis et al. 2019b).

\section{CONCLUSION}

Our study provides a detailed picture of the impact of road fatalities on the life expectancy of South Africans. Using data from the Injury Mortality Survey (Matzopoulos et al. 2013b; Matzopoulos et al. 2015a) we estimate the mortality rate from RTIs to be about 33 per 100,000 inhabitants. RTIs therefore pose a considerable public health challenge in South Africa. The typical victim is young and male, almost one-third of deaths were recorded among men aged between 15 and 29 years. An 80\% reduction in mortality due to RTIs could have a substantial impact on life expectancy and YPLL, in particular for men, they could live an additional 0.85 years and females 0.30 years. In total, road traffic crashes account for 66,349 and 24,744 YPLL for males and females, respectively. This is consistent with results seen worldwide in which males have significant higher motor vehicle crash and deaths rates than females, and young adults are the highest-risk age group for motor vehicle mortality (Chandran et al. 2013). Our estimated potential gains in life expectancy and in YPLL are comparable to other studies calculating potential for a reduction in road traffic fatalities to zero for Brazil (life expectancy is reduced by 0.8 years for males and 0.2 years for females (Chandran et al. 2013) and China (life expectancy is reduced by 0.54 for males and 0.28 years for females ( $\mathrm{Li}$ et al. 2017).

The good news is that there is considerable knowledge regarding road safety interventions and many countries have managed to reduce RTIs. For example the WHO (WHO, 2017) provides a technical package on road safety and a number of studies examine the (cost) effectiveness of road safety interventions in different countries. To our knowledge there is no assessment of the (cost) effectiveness of interventions in South Africa. Such an assessment would provide the evidence on which a countrywide road safety strategy. Based on our discussion the interventions should most likely be targeted at the main risk factors for RTIs: Seat-belt wearing, Speed, drink driving, young drivers (graduated drivers licensing) and road infrastructure. Since interventions have been shown to be highly effective in other countries a $80 \%$ reduction of deaths due to RTIs appears to be feasible. The bad news is that despite this knowledge and a public commitment to reduce RTIs in the government's National Road Safety Strategy (Arrive Alive 2010), RTI rates per 100,000 have not been reduced over the past decade. While South Africa has got comprehensive road safety legislation, these laws are poorly enforced. However, as studies by economists at Stellenbosch University suggest, stricter enforcement may only be part of the solution. Compliance 
does not only depend on the risk of detection and the monetary and legal consequences, but also on social norms that guide behaviour (Du Plessis et al. 2019b; 2020).

In summary, our analysis and discussion suggest that RTIs are a considerable public health burden in South Africa but that cost-effective interventions exist to reduce RTIs. The choice and effectiveness of interventions are largely shaped by factors outside the health system (Wesson et al. 2016) and this calls for more interdisciplinary research to develop an improved road safety strategy for South Africa and to document and evaluate its impact. 


\section{APPENDIX}

\section{Data Quality}

Originally, we set out to compare the actual time series data on life expectancy with a counterfactual trajectory assuming a reduction in RTIs (similar to the analysis by (Sharkey und Friedson 2019; Symons et al. 2019). However, at the data collection stage it became obvious that time series data from Statistics South Africa and other sources were insufficient for such an analysis. In order to measure population health and calculate life expectancy, the mortality data must be reliable, valid and comparable. To illustrate the data problems take the estimates of life expectancy, these can vary by over 10 years for the same point in time, depending on the data source used (Stats SA 2009); (UN 2019a); (WHO 2014); (WorldBank 2019). These data discrepancies persist despite various South Africa initiatives that have identified and addressed data deficiencies. The completeness of death registration has considerably improved (Bradshaw et al. 1998); (Dorrington et al. 2001); (Dorrington et al. 2004); (Prinsloo et al. 2017)) and recent estimates indicate that completeness for persons aged more than 2 years is about $90 \%$ (Dorrington et al. 2014); (Prinsloo et al. 2017). However, there are still concerns about the quality of data relating to the cause of death, namely, misclassification of injury deaths (Matzopoulos et al. 2013a; Matzopoulos et al. 2015b); (Pillay-van Wyk et al. 2016a)). Previous studies (Chokotho et al. 2013) reported a consistent underrepresentation of deaths on official data sources, namely of pedestrians deaths, while passengers deaths are overrepresented in the police data when compared to the Injury Mortality Survey data. Other authorities such as RTMC, also use police data, but the proportions released by the RTMC (2008) are closer to the Injury Mortality Survey, suggesting that RTMC might be aware of the underreporting of the police data and use some statistical modelling to generate adjusted estimates. Although these estimates may still underrepresent the extent of pedestrian deaths (Chokotho et al. 2013). 


\section{REFERENCES}

Aragón, Tomás J.; Lichtensztajn, Daphne Y.; Katcher, Brian S.; Reiter, Randy; Katz, Mitchell H. (2008): Calculating expected years of life lost for assessing local ethnic disparities in causes of premature death. In: BMC public health 8 (1), S. 1-12.

Arrive Alive (2010): Decade of Action and Arrive Alive - National Road Safety Strategy 2011-2020.

Bor, Jacob; Rosen, Sydney; Chimbindi, Natsayi; Haber, Noah; Herbst, Kobus; Mutevedzi, Tinofa et al. (2015): Mass HIV treatment and sex disparities in life expectancy: demographic surveillance in rural South Africa. In: PLoS medicine 12 (11).

Bradshaw, Debbie; Kielkowski, Danuta; Sitas, Freddy (1998): New birth and death registration forms-a foundation for the future, a challenge for health workers? In: South African Medical Journal 88 (8), S. 971-974.

Chandran, Aruna; Kahn, Geoffrey; Sousa, Tanara; Pechansky, Flavio; Bishai, David; Hyder, Adnan (2013): Impact of road traffic deaths on expected years of life lost and reduction in life expectancy in Brazil. In: Demography 50 (1), S. 229-236.

Chokotho, Linda Carolyn; Matzopoulos, R.; Myers, J. E. (2013): Assessing quality of existing data sources on road traffic injuries (RTIs) and their utility in informing injury prevention in the Western Cape Province, South Africa. In: Traffic injury prevention 14 (3), S. 267-273.

Daniels, Stijn; Martensen, Heike; Schoeters, Annelies; van den Berghe, Wouter; Papadimitriou, Eleonora; Ziakopoulos, Apostolos et al. (2019): A systematic cost-benefit analysis of 29 road safety measures. In: Accident Analysis \& Prevention 133.

Dorrington, Rob; Bourne, David; Bradshaw, Debbie; Laubscher, Ria; Timæus, Ian M. (2001): The impact of HIV/AIDS on adult mortality in South Africa: Medical Research Council Cape Town.

Dorrington, Rob; Bradshaw, Debbie; Laubscher, Ria; Nannan, N. (2014): Rapid mortality surveillance report 2012: South African Medical Research Council Cape Town.

Dorrington, Rob; Moultrie, Tom A.; Timæus, Ian (2004): Estimation of mortality using the South African Census 2001 data: Centre for Actuarial Research, University of Cape Town.

Du Plessis, Sophia; Hartig, Bjoern; Jansen, Ada; Siebrits, Krige (2019a): Improving payment of traffic fines with financial incentives: Discounts versus penalties. Stellenbosch Economic Working Papers.

Du Plessis, Sophia; Jansen, Ada; Siebrits, Krige; Bantjes, Jason; Boshoff, Christo (2019b): Improving Traffic Law Enforcement in South Africa - Improving knowledge with a survey. Mimeo.

Du Plessis, Sophia; Jansen, Ada; Siebrits, Krige (2020): The limits of laws: Traffic law enforcement in South Africa. In: South African Journal of Economic and Management Sciences 23, S. 1-11. Online verfügbar unter http://www.scielo.org.za/scielo.php?script=sci_arttext\&pid=S2222-34362020000100011\&nrm=iso.

Foreman, Kyle J.; Marquez, Neal; Dolgert, Andrew; Fukutaki, Kai; Fullman, Nancy; McGaughey, Madeline et al. (2018): Forecasting life expectancy, years of life lost, and all-cause and cause-specific mortality for 250 causes of death: reference and alternative scenarios for 2016-40 for 195 countries and territories. In: The Lancet 392 (10159), S. 2052-2090.

Friedman, Howard Steven (2020): Ultimate Price: The Value We Place on Life: University of California Press.

IHME (2018): GBD Compare Data Visualization. Online verfügbar unter http://vizhub.healthdata.org/gbdcompare, zuletzt geprüft am 15 of January 2020.

IRTAD (2020): International Traffic Safety Data and Analysis Group. Online verfügbar unter https://www.itfoecd.org/IRTAD, zuletzt geprüft am 25th March 2020.

Isaacs, Lauren (2020): Groote Schuur: Two-Thirds Drop in Trauma Cases Due to Lochdown's Booze Ban, 08.04.2020. Online verfügbar unter https:// ewn.co.za/2020/04/08/groote-schuur-two-thirds-drop-intraumacases-due-to-lockdown-s-booze-ban, zuletzt geprüft am 09.08.2020.

Li, Qingfeng; Ma, S.; Bishai, D.; Hyder, Adnan Ali (2017): Potential gains in life expectancy by improving road safety in China. In: Public health 144, S57-S61. 
Matzopoulos, Richard; Prinsloo; Bradshaw, Debbie; Pillay-van Wyk, Victoria; Gwebushe, Nomonde; Mathews, Shanaaz et al. (2013a): The Injury Mortality Survey: A national study of injury mortality levels and causes in South Africa in 2009. In: Cape Town: Medical Research Council.

Matzopoulos, Richard; Prinsloo, Megan; Bradshaw, Debbie; Pillay-van Wyk, Victoria; Gwebushe, Nomonde; Mathews, Shanaaz et al. (2013b): The Injury Mortality Survey: A national study of injury mortality levels and causes in South Africa in 2009. In: Cape Town: Medical Research Council.

Matzopoulos, Richard; Prinsloo, Megan; Wyk, Victoria Pillay-van; Gwebushe, Nomonde; Mathews, Shanaaz; Martin, Lorna J. et al. (2015a): Injury-related mortality in South Africa: a retrospective descriptive study of postmortem investigations. In: Bulletin of the World Health Organization 93, S. 303-313.

Matzopoulos, Richard; Prinsloo, Megan; Wyk, Victoria Pillay-van; Gwebushe, Nomonde; Mathews, Shanaaz; Martin, Lorna J. et al. (2015b): Injury-related mortality in South Africa: a retrospective descriptive study of postmortem investigations. In: Bulletin of the World Health Organization 93, S. 303-313.

Matzopoulos, Richard; Walls, Helen; Cook, Sarah; London, Leslie (2020): South Africa's COVID-19 alcohol sales ban: the potential for better policy-making. In: International Journal of Health Policy and Management.

Peden, Margie; Scurfield, Richard; Sleet, David; Hyder, Adnan A.; Mathers, C.; Jarawan, Eva et al. (2004): World report on road traffic injury prevention: World Health Organization.

Pillay-van Wyk, Victoria; Msemburi, William; Dorrington, Rob; Neethling, I.; Nannan, N.; Groenewald, P. (2016a): Second national burden of disease study for South Africa: Cause-of-death profile for Free State, 19972012. In: Cape Town: South African Medical Research Council.

Pillay-van Wyk, Victoria; Msemburi, William; Laubscher, Ria; Dorrington, Rob E.; Groenewald, Pam; Glass, Tracy et al. (2016b): Mortality trends and differentials in South Africa from 1997 to 2012: second National Burden of Disease Study. In: The Lancet Global Health 4 (9), e642-e653.

Preston, Samuel H.; Guillot, Michel.; Heuveline, Patrick. (2000): Demography, measuring and modeling population processes. Malden: Blackwell Publishers.

Prinsloo, Megan (2019): Estimating injury mortality in South Africa and identifying urban-rural differences. $\mathrm{PhD}$ thesis. Faculty of Health Sciences.

Prinsloo, Megan; Bradshaw, Debbie; Joubert, Jané; Matzopoulos, Richard; Groenewald, Pam (2017): South Africa's vital statistics are currently not suitable for monitoring progress towards injury and violence Sustainable Development Goals. In: SAMJ: South African Medical Journal 107 (6), S. 470-471.

Ralaidovy, Ambinintsoa H.; Bachani, Abdulgafoor M.; Lauer, Jeremy A.; Lai, Taavi; Chisholm, Dan (2018): Cost-effectiveness of strategies to prevent road traffic injuries in eastern sub-Saharan Africa and Southeast Asia: new results from WHO-CHOICE. In: Cost effectiveness and resource allocation 16 (1), S. 59.

Sharkey, Patrick; Friedson, Michael (2019): The impact of the homicide decline on life expectancy of African American males. In: Demography 56 (2), S. 645-663.

Stats SA (2009): Statistics South Africa. Online verfügbar unter http://www.statssa.gov.za/publications/SAStatistics/SAStatistics2009.pdf.

Symons, John; Howard, Eric; Sweeny, Kim; Kumnick, Margarita; Sheehan, Peter (2019): Reduced road traffic injuries for young people: A preliminary investment analysis. In: Journal of Adolescent Health 65 (1), S34-S43.

UN (2019a): “2019 Revision of World Population Prospects”. Online verfügbar unter https://population.un.org/wpp/.

UN (2019b): “2019 Revision of World Population Prospects”. Department of Economic and Social AffairsPopulation Dynamics. Online verfügbar unter https://population.un.org/wpp/.

Verster, Tanja; Fourie, Erika (2018): The good, the bad and the ugly of South African fatal road accidents. In: South African Journal of Science 114 (7-8), S. 63-69.

Wesson, Hadley K. H.; Boikhutso, Nkuli; Hyder, Adnan A.; Bertram, Melanie; Hofman, Karen J. (2016): Informing road traffic intervention choices in South Africa: the role of economic evaluations. In: Global health action 9 (1), S. 30728. 
WHO (2014): Global Health Estimates 2014 Summary Tables: Death by cause, age and sex, by WHO region, 2000-2012. In: Geneva, Switzerland: Geneva, WHO.

WHO (2017): WHO. 2017. Save LIVES-a road safety technical package. Geneva: WHO. Geneva: WHO.

WHO (2018): Global status report on road safety. Geneva: World Health Organization. Online verfügbar unter https://www.who.int/violence_injury_prevention/road_safety_status/2018/en/.

WHO (2019): Road Traffic deaths data by country. Global Health Observatory. Online verfügbar unter https://apps.who.int/gho/data/node.main.A997.

WHO (2020): Global Health Observatory (GHO) data: Life expectancy. Online verfügbar unter https://www.who.int/gho/mortality_burden_disease/life_tables/situation_trends_text/en/.

Wijnen, Wim; Weijermars, Wendy; Schoeters, Annelies; van den Berghe, Ward; Bauer, Robert; Carnis, Laurent et al. (2019): An analysis of official road crash cost estimates in European countries. In: Safety science 113, S. 318-327.

WorldBank (2019): Life expectancy at birth. Online verfügbar unter https://data.worldbank.org/indicator/SP.DYN.LE00.IN?end=2017\&locations=ZG-ZA\&start=1960\&view=chart. 